\title{
Experimental Investigation and Optimization of Material Properties of Brass at Different Temperature Conditions Using Taguchi Technique
}

\author{
V Dharam Singh ${ }^{1}$ M Manzoor Hussain ${ }^{2}$, Swadesh Kumar Singh $^{3}$ \\ ${ }^{1}$ Mechanical Engineering Department, Muffakham Jah College of Engineering and Technology Hyderabad-500034, \\ Telangana, India \\ ${ }^{2}$ Mechanical Engineering Department, Jawaharlal Nehru Technological University Hyderabad-500085, Telangana, \\ India \\ ${ }^{3}$ Mechanical Engineering Department, GRIET, Hyderabad- 500090, Telangana, India \\ Corresponding author. E-mail address: dharamsingh10@gmail.com: Tel.: +91 9494060419
}

\begin{abstract}
The present investigation deals with the optimization of the parameters for better formability behaviour of brass sheet metal under uniaxial isothermal Tensile Test by using Taguchi Design of Experiments (DoE). The standard L9 $\left(3^{3}\right)$ Orthogonal Array was formulated to run the experiments based on Taguchi robust design and accordingly uniaxial isothermal Tensile Test conducted at orientation $\left(0^{0}, 45^{0}\right.$ and $\left.90^{\circ}\right)$, temperature $\left(300^{\circ} \mathrm{C}, 400^{\circ} \mathrm{C}\right.$, and $\left.500{ }^{\circ} \mathrm{C}\right)$, and strain rate $\left(0.001,0.01\right.$ and $\left.0.1 \mathrm{~s}^{-1}\right)$. Analysis of S/N ratios for Ultimate tensile strength and \% elongation reported the optimum condition as orientation at level 1 (in degrees), temperature at level 1 (in degree Celsius), and strain rate at level $3\left(\mathrm{~s}^{-1}\right)$ and orientation at level 1 (in degrees), temperature at level 3 (in degree Celsius), and strain rate at level $1\left(\mathrm{~s}^{-1}\right)$ respectively. ANOVA analysis reported the Temperature as the most significant parameter and its contribution are about $62.109 \%$ and $71.924 \%$ for ultimate tensile strength and \% elongation respectively.
\end{abstract}

\section{Introduction:}

Sheet metal forming is one of the cutting-edge technologies for production of large variety of products in almost all sectors of industries such as aircraft, automotive, food and home appliance industries [1]. In sheet metal forming process, the blank of sheet metal is converted into a desired shape by light plastic deformation with the use of a suitable tooling. In present days high-strength material with low plasticity and difficult-to-form metals can also be formed under cold, warm and hot forming conditions [2,3]. The mechanical properties of the sheet metal are an important parameters and inadequate consideration of this parameters in the design of sheet metal forming processes leads to defective products $[4,5]$. Study of properties and behaviour of material under different variable conditions is utmost necessary before proceeding for actual manufacturing of the products.

Brass are substitutional alloys of copper $(\mathrm{Cu})$ and zinc $(\mathrm{Zn})$. As the $\mathrm{Zn}$ content increases in $\mathrm{Cu}$, its tensile strength and wear resistance increases upto $45 \mathrm{wt} . \%$ and upon exceeding $45 \mathrm{wt} . \%$ its strength deteriorated rapidly [6]. The brass consists of 30-45 wt.\% Zn mostly used in industrial application $[7,8]$. By adding alloy elements
$(\mathrm{Al}, \mathrm{Sn}, \mathrm{Ni}, \mathrm{Fe})$ properties are modified and its performance can be improved $[9,10]$. Brass can be classified into $\alpha$ brass, $\alpha+\beta$ ' brass, and $\beta$ ' brass, and their microstructures are changes with $\mathrm{Zn}$ content. The strength and ductility of $\alpha$ brass are superior than that of pure $\mathrm{Cu}$ at room temperature; $\beta$ ' brass is hard and less tough; $\alpha+\beta$ ' brass stronger than $\alpha$ brass and tougher than $\beta^{\prime}$ brass, hence its applications are wider. Moreover, the high-temperature $\beta$ phase is softer than the low-temperature $\beta$ ' phase, which results better hot workability of $\alpha+\beta$ ' brass [11]. Therefore $\alpha+\beta^{\prime}$ brass selected for this study, which explores the effects of high temperature conditions on the mechanical properties of brass. When metals are subjected to plastic deformation under high-temperature, leads to dynamic recovery and dynamic recrystallization to occur $[12,13]$. The addition of $\mathrm{Zn}$ to the brass will decreases the stacking fault energy and dynamic recovery leads to dynamic recrystallization to improve the formability at hightemperature [14]. In general, dislocation motion in metals is easier with rise in temperature, causes an easier plastic deformation and more ductility. However, an intermediate-temperature brittleness phenomenon was found in $\mathrm{Cu}$ alloys [15]. The dual-phase brass (40 wt.\% $\mathrm{Zn}$ ) has a higher tensile strength than the single-phase brass (30 wt.\% $\mathrm{Zn})$ at room temperature [16]. 
Taguchi Design of experiment (DOE) method can optimize parameters with minimum experimental runs and reduce the time and cost of the experiments. Using this one can recognize parameters that may affect the quality of the products [17]. Analysis of variance (ANOVA) was proposed by Sir Ronald Fisher [19]. ANOVA analysis was carried out for a 5\% significance level (i.e., for $95 \%$ confidence level). The main purpose of ANOVA is to find out, significant parameters which essentially influences the performance characteristics $[20,21]$.

Therefore, uniaxial isothermal tensile test conducted and the effects of various elevated temperatures, strain rates and orientations on the mechanical properties and behaviour of the brass material were explored.

\section{Taguchi Design Of Experiment}

\subsection{Identification of Factors and Responses}

In the present study parameters identified for investigation are temperature, strain, orientation. The selected control factors and their levels are depicted in table 1 .

Table 1. Control factors and their levels

\begin{tabular}{|c|c|c|c|}
\hline \multirow{2}{*}{$\begin{array}{c}\text { Control } \\
\text { Factors }\end{array}$} & \multicolumn{3}{|c|}{ Levels } \\
\cline { 2 - 4 } & $\mathbf{1}$ & $\mathbf{2}$ & $\mathbf{3}$ \\
\hline A: Orientation & 300 & 400 & 500 \\
\hline B: Temperature & 0.1 & 0.01 & 0.001 \\
\hline C: Strain rate & $0^{0}$ & $45^{0}$ & $90^{0}$ \\
\hline
\end{tabular}

\subsection{Design of Orthogonal Array}

Table 2. Formulation of $\mathrm{L}_{9}\left(3^{3}\right)$ orthogonal array

\begin{tabular}{|c|c|c|c|}
\hline \multirow[b]{2}{*}{ Run } & \multicolumn{3}{|c|}{ Test Parameters } \\
\hline & $\begin{array}{c}\text { Orientation } \\
\left({ }^{0}\right) \\
\text { A }\end{array}$ & $\begin{array}{c}\text { Temperature } \\
\left(0^{0}\right) \\
\text { B }\end{array}$ & $\begin{array}{c}\text { Strain } \\
\text { Rate }\left(\mathrm{S}^{-1}\right) \\
\text { C }\end{array}$ \\
\hline 1 & $0^{0}$ & 300 & 0.1 \\
\hline 2 & $0^{0}$ & 400 & 0.01 \\
\hline 3 & $0^{0}$ & 500 & 0.001 \\
\hline 4 & $45^{0}$ & 300 & 0.01 \\
\hline 5 & $45^{0}$ & 400 & 0.001 \\
\hline 6 & $45^{0}$ & 500 & 0.1 \\
\hline 7 & $90^{0}$ & 300 & 0.001 \\
\hline 8 & $90^{0}$ & 400 & 0.1 \\
\hline 9 & $90^{0}$ & 500 & 0.01 \\
\hline
\end{tabular}

\section{Experimental Procedure}

\subsection{Specimen Preparation}

Tensile test specimens made of cold rolled brass sheet of $1 \mathrm{~mm}$ thickness as per sub-sized ASTM E08/E8M-11 standard.
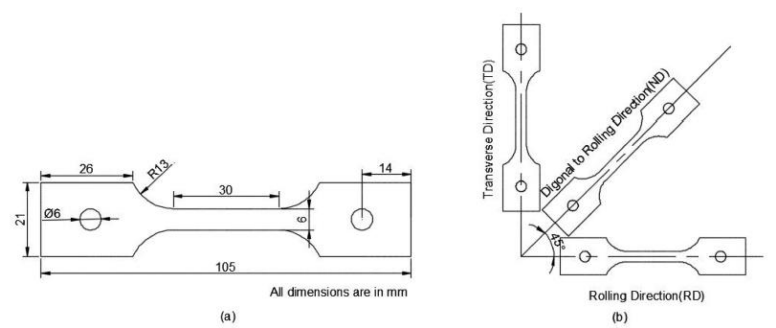

Figure1 : (a). Schematic of the tensile test specimen as per sub sized ASTM E08/E8M-11 standard and (b). Schematic of different orientations of a sheet

\subsection{Experimental Set-up}

The experiment was performed on BISS Electra $50 \mathrm{KN}$ Servo Electric UTM under quasi-static straining condition. It is equipped with two zone split furnace, maximum $1000{ }^{\circ} \mathrm{C}$ heating capacity with $\pm 3{ }^{\circ} \mathrm{C}$ accuracy, temperature of specimen was controlled through 3 thermocouples.

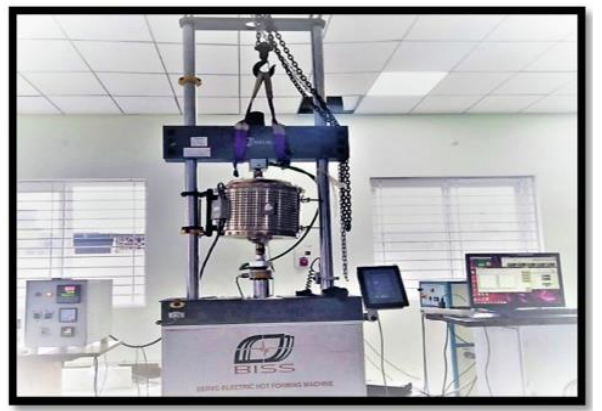

Figure 2 : Uniaxial Tensile Test Machine

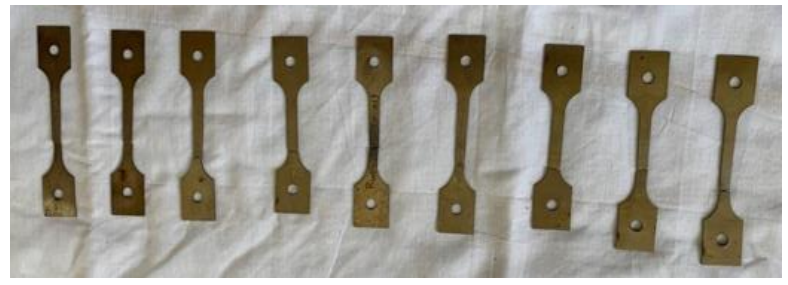

Figure 3 : Uniaxial Tensile Test Specimens in all orientation

Table 3 : Experimental result for Tensile strength

\begin{tabular}{|c|c|c|c|c|c|}
\hline \multirow{2}{*}{ Run } & \multicolumn{5}{|c|}{ Experiment Results } \\
\cline { 2 - 6 } & $\begin{array}{c}\text { Orienta } \\
\left.\text { tion } \mathbf{(}^{\mathbf{(}}\right)\end{array}$ & $\begin{array}{c}\text { Temper } \\
\text { ature } \\
\left(\mathbf{0}^{\mathbf{0}}\right)\end{array}$ & $\begin{array}{c}\text { Strain } \\
\text { Rate } \\
\left(\mathbf{S}^{-1}\right)\end{array}$ & $\begin{array}{c}\text { UTS } \\
(\mathbf{M p a})\end{array}$ & $\begin{array}{c}\text { \% } \\
\text { EL }\end{array}$ \\
\hline 1 & $0^{0}$ & 300 & 0.1 & 354 & 36 \\
\hline 2 & $0^{0}$ & 400 & 0.01 & 202 & 39 \\
\hline 3 & $0^{0}$ & 500 & 0.001 & 126 & 43 \\
\hline 4 & $45^{0}$ & 300 & 0.01 & 341 & 32 \\
\hline 5 & $45^{0}$ & 400 & 0.001 & 198 & 35 \\
\hline 6 & $45^{0}$ & 500 & 0.1 & 126 & 39 \\
\hline 7 & $90^{0}$ & 300 & 0.001 & 341 & 31 \\
\hline 8 & $90^{0}$ & 400 & 0.1 & 181 & 34 \\
\hline 9 & $90^{0}$ & 500 & 0.01 & 123 & 36 \\
\hline
\end{tabular}

\section{Analysis of Results}

\subsection{Analysis of S/N Ratio}

Signal-to Noise Ratio ( $S / N$ ratio) analysis is an optimizing tool used for the measurement of quality 
deviation from the target value. The $\mathrm{S} / \mathrm{N}$ ratio carried out in this work is executed based on the larger the better for ultimate tensile strength and \% elongation using equation 1 and 2 respectively. Results are reported in table

Objective Function : Larger-the better (LTB) : It is selected when the aim is to maximize the response

$$
\mathrm{SNR}=-10 \log _{10}\left[\frac{1}{n} \sum_{i=1}^{n}\left(\frac{1}{a_{i}^{2}}\right)\right]
$$

Where

$\mathrm{S} / \mathrm{N}$ représents signal to noise ratio.

$n$ represents number to test

$a_{i}$ represents the ultimate tensile strength and

$\%$ elongation values

Table 4. Computation of $\mathrm{S} / \mathrm{N}$ ratio for Ultimate Tensile Strength

\begin{tabular}{|c|c|c|c|c|c|}
\hline \multirow{2}{*}{ Expts } & \multicolumn{3}{|c|}{ Parameters } & \multicolumn{2}{c|}{$\begin{array}{c}\text { S/N } \\
\text { Ratio }\end{array}$} \\
\cline { 2 - 6 } & $\begin{array}{c}\text { Trient } \\
\text { ation } \\
\mathbf{( 0 )}^{\mathbf{0}}\end{array}$ & $\begin{array}{c}\text { Tempe } \\
\text { rature } \\
\left(\mathbf{0}^{\mathbf{0}}\right)\end{array}$ & $\begin{array}{c}\text { Strain } \\
\text { Rate } \\
\left(\mathrm{S}^{-1}\right)\end{array}$ & $\begin{array}{c}\text { UTS } \\
\text { (Mpa) }\end{array}$ & \% EL \\
\hline 1 & $0^{0}$ & 300 & 0.1 & 50.98 & 31.12 \\
\hline 2 & $0^{0}$ & 400 & 0.01 & 46.10 & 31.82 \\
\hline 3 & $0^{0}$ & 500 & 0.001 & 42.00 & 32.66 \\
\hline 4 & $45^{0}$ & 300 & 0.01 & 50.65 & 30.10 \\
\hline 5 & $45^{0}$ & 400 & 0.001 & 45.93 & 30.88 \\
\hline 6 & $45^{0}$ & 500 & 0.1 & 42.00 & 31.82 \\
\hline 7 & $90^{0}$ & 300 & 0.001 & 50.65 & 29.82 \\
\hline 8 & $90^{0}$ & 400 & 0.1 & 45.15 & 30.62 \\
\hline 9 & $90^{0}$ & 500 & 0.01 & 41.79 & 31.12 \\
\hline
\end{tabular}

The mean $\mathrm{S} / \mathrm{N}$ ration values of each parameter for each level have been investigated and presented in table 4 . It was observed that from table 5 and table 6 and also from figure 4 and figure 5 that the optimum condition for brass sheet metal in uniaxial tensile test for ultimate tensile strength and \% elongation are reported as orientation at level 1 (in degrees), temperature at level 1(degree Celsius), and strain rate at level $3\left(\mathrm{~s}^{-1}\right)$ and orientation at level 1 (in degrees), temperature at level 3(degree Celsius), and strain rate at level $1\left(\mathrm{~s}^{-1}\right)$ respectively. From the table 5 and table 6 it very clear that rank 1 denotes that temperature is most significant and contributing factor in both the cases under uniaxial tensile test.

Table 5. Mean of S/N Ratio for Ultimate Tensile Strength

\begin{tabular}{|c|c|c|c|}
\hline Level & Orientation & Temperature & $\begin{array}{c}\text { Strain } \\
\text { Rate }\end{array}$ \\
\hline 1 & $\mathbf{4 6 . 3 6}$ & $\mathbf{5 0 . 7 6}$ & $\mathbf{4 6 . 2 0}$ \\
\hline 2 & 46.20 & 45.73 & 46.19 \\
\hline 3 & 45.87 & 41.94 & 46.05 \\
\hline Delta & 0.50 & 8.83 & 0.15 \\
\hline Rank & 2 & 1 & 3 \\
\hline
\end{tabular}

Table 6. Mean of S/N Ratio for \% Elongation

\begin{tabular}{|c|c|c|c|}
\hline Level & Orientation & Temperature & Strain Rate \\
\hline 1 & $\mathbf{3 1 . 8 7}$ & 30.35 & 31.13 \\
\hline 2 & 30.94 & 31.11 & 31.02 \\
\hline 3 & 30.53 & $\mathbf{3 1 . 8 7}$ & $\mathbf{3 1 . 1 9}$ \\
\hline Delta & 1.34 & 1.52 & 0.18 \\
\hline Rank & 2 & 1 & 3 \\
\hline
\end{tabular}

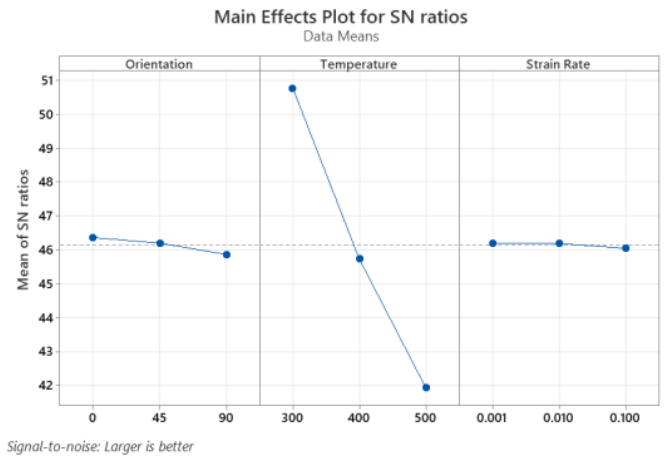

Figure 4 : Main effects plots for SN ratio for ultimate tensile strength

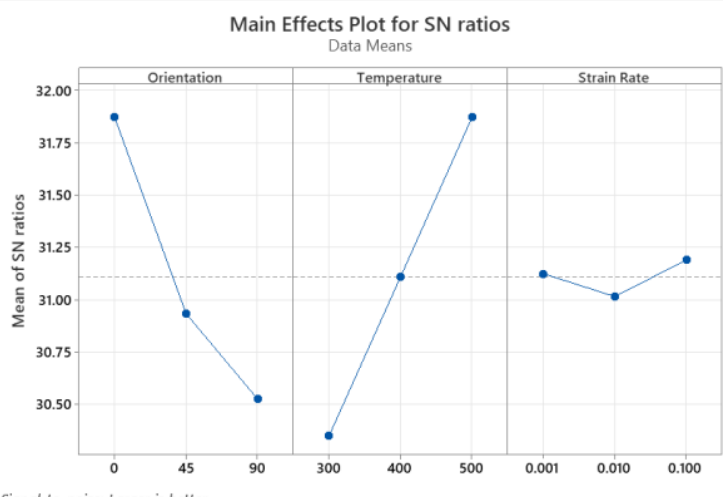

Figure 5 : Main effects plots for SN ratio for $\%$ elongation

\subsection{Development of mathematical model with regression analysis}

Using the experimental response, mathematical regression model has been developed in MINITAB 19 software. The regression model for Ultimate Tensile Strength and \% Elongation reported as equation 2, equation 3. For all the cases the R-sq and R-sq(adj) are reported. R-sq is the wellness response of regression model usually lie in between $0 \%$ to $100 \%$. $0 \%$ denotes a model that does not states any of the variation in the response variable around its mean and $100 \%$ denotes a model that states all of the variation in the response variable around its mean. Generally, larger the R-sq, better the regression model fits. In the present for all cases the regression models are closer to $100 \%$ hence one can say that these models having better regression fit. From figure 6 depicts the different strain rates for different shaded areas (i.e. contour plot of Strain Rate Vs Temperature, Orientation). Figure 7 represents the surface plot of Strain Rate Vs Temperature, Orientation.

Regression Equation for ultimate tensile strength $\mathrm{UTS}=561+1.33$ Orientation -0.890 Temperature +581 Strain Rate -0.00253 Orientation* Temperature -12.50 Orientation*Strain Rate +0.09 Temperature * Strain Rate 
$\mathrm{R}-\mathrm{sq}=98.54 \% \mathrm{R}-\mathrm{sq}(\operatorname{adj})=94.15 \%$

Regression Equation for \% elongation

$\% \mathrm{EL}=18.63+0.0475$ Orientation +0.04895

Temperature +69.6 Strain Rate -0.000256

Orientation*Temperature -0.064 Orientation*

Strain Rate -0.1420 Temperature*Strain Rate (3)

$R-s q=98.93 \% R-s q(\operatorname{adj})=95.73 \%$

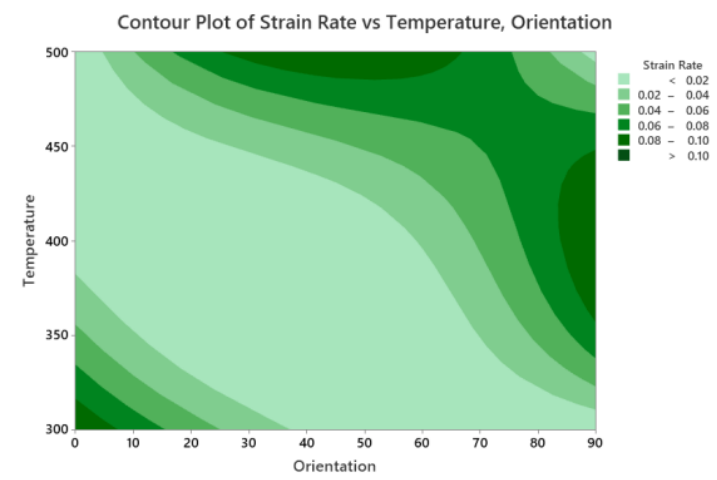

Figure 6 : Contour plot of strain rate vs temperature \& orientation

Surface Plot of Strain Rate vs Temperature, Orientation

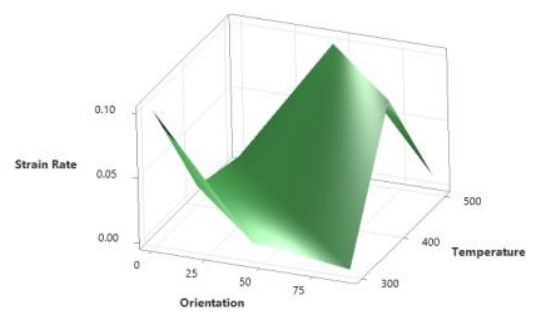

Figure 7 : Surface plot of strain rate vs temperature \& orientation

\section{Analysis of variance (ANOVA)}

Analysis of variance developed by Sir Ronald Fisher [17]. In the present paper it applied to evaluate the significance level of $5 \%$, at $95 \%$ confidence level.The primary aim of ANOVA is to investigate the parameter that significantly influence the response variables [19].

In this paper ANOVA was carried out for all the cases and shown in table 7 and table 8. From ANOVA analysis as shown in table 7 and table 8 and also from figure 8 and figure 9 it is clear that temperature is most significant parameter and its contribution are about $62.109 \%$ and $71.924 \%$. Figure 10 and figure 11 depicts the goodness fitting of normal probability plot for ultimate tensile strength and \% elongation under the uniaxial tensile test.
Table 7. Analysis of Variance (ANOVA) for Ultimate tensile strength

\begin{tabular}{|l|c|c|c|c|c|c|}
\hline \multicolumn{1}{|c|}{ Source } & DF & Adj SS & $\begin{array}{c}\text { Adj } \\
\text { MS }\end{array}$ & $\begin{array}{c}\text { F- } \\
\text { Value }\end{array}$ & $\begin{array}{c}\text { P- } \\
\text { Value }\end{array}$ & $\begin{array}{c}\% \\
\text { Cont }\end{array}$ \\
\hline Regression & 6 & 75511.9 & 12585.3 & 22.47 & 0.043 & \\
\hline Orientation & 1 & 363 & 363 & 0.65 & 0.505 & 3.69 \\
\hline Temperature & 1 & 6110.1 & 6110.1 & 10.91 & 0.081 & 62.109 \\
\hline Strain Rate & 1 & 131.2 & 131.2 & 0.23 & 0.676 & 1.334 \\
\hline $\begin{array}{l}\text { Orientation* } \\
\text { Temperature }\end{array}$ & 1 & 261.9 & 261.9 & 0.47 & 0.565 & 2.662 \\
\hline $\begin{array}{l}\text { Orientation* } \\
\text { Strain Rate }\end{array}$ & 1 & 2410.9 & 2410.9 & 4.3 & 0.174 & 24.507 \\
\hline $\begin{array}{l}\text { Temperature* } \\
\text { Strain Rate }\end{array}$ & 1 & 0.6 & 0.6 & 0 & 0.977 & 0.006 \\
\hline Error & 2 & 1120.1 & 560 & & & 5.692 \\
\hline Total & 8 & 76632 & 9837.7 & & & 100 \\
\hline
\end{tabular}

Table 8. Analysis of Variance (ANOVA) for \% Elongation

\begin{tabular}{|l|c|c|c|c|c|c|}
\hline \multicolumn{1}{|c|}{ Source } & DF & Adj SS & $\begin{array}{c}\text { Adj } \\
\text { MS }\end{array}$ & $\begin{array}{c}\text { F- } \\
\text { Value }\end{array}$ & $\begin{array}{c}\text { P- } \\
\text { Value }\end{array}$ & $\begin{array}{c}\% \\
\text { Cont }\end{array}$ \\
\hline Regression & 6 & 111.683 & 18.6138 & 30.87 & 0.032 & \\
\hline Orientation & 1 & 0.459 & 0.4587 & 0.76 & 0.475 & 1.783 \\
\hline Temperature & 1 & 18.499 & 18.4994 & 30.68 & 0.031 & 71.924 \\
\hline Strain Rate & 1 & 1.885 & 1.8846 & 3.13 & 0.219 & 7.327 \\
\hline $\begin{array}{l}\text { Orientation* } \\
\text { Temperature }\end{array}$ & 1 & 2.677 & 2.6771 & 4.44 & 0.17 & 10.408 \\
\hline $\begin{array}{l}\text { Orientation* } \\
\text { Strain Rate }\end{array}$ & 1 & 0.062 & 0.0624 & 0.1 & 0.778 & 0.243 \\
\hline $\begin{array}{l}\text { Temperature* } \\
\text { Strain Rate }\end{array}$ & 1 & 1.536 & 1.5355 & 2.55 & 0.252 & 5.970 \\
\hline Error & 2 & 1.206 & 0.603 & & & 2.344 \\
\hline Total & 8 & 112.889 & 25.7207 & & & 100 \\
\hline
\end{tabular}

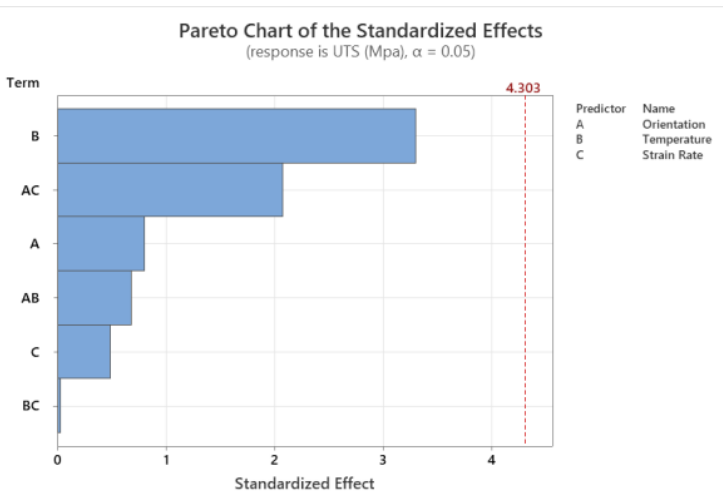

Figure 8 : Pareto chart of the standardized effects for ultimate tensile strength

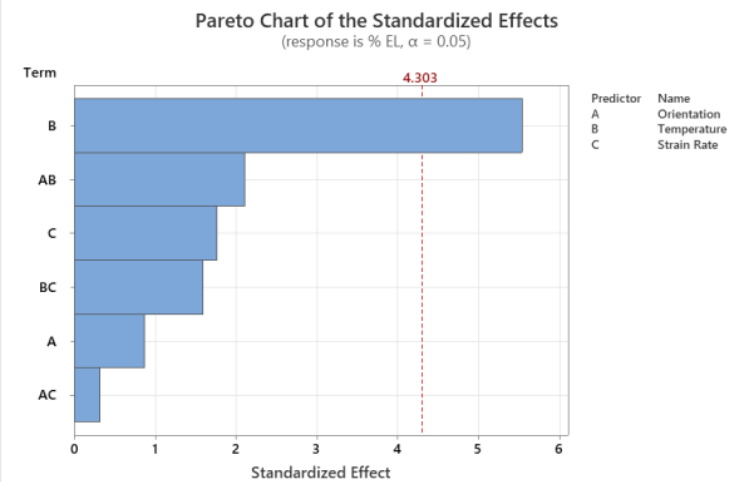

Figure 9 : Pareto chart of the standardized effects for $\%$ elongation 


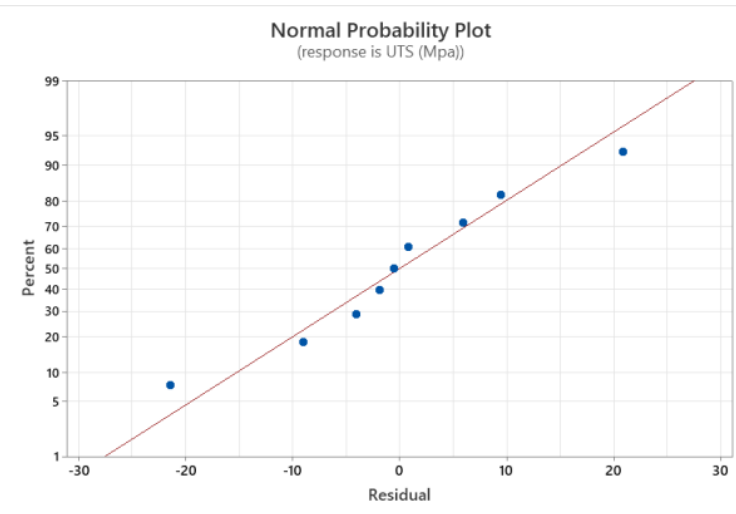

Figure 10 : Normal probability plots for ultimate tensile strength

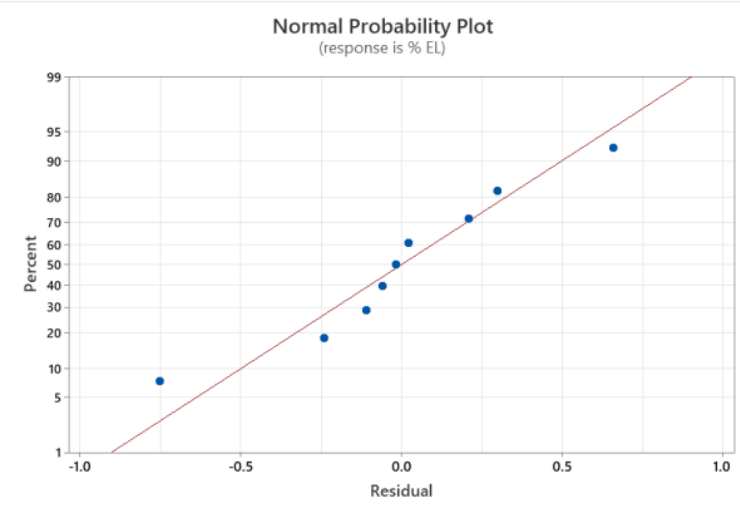

Figure 11 : Normal probability plots for $\%$ elongation

\section{Confirmation Experiment}

Taguchi recommended the Confirmation Test essentially to verify the test results [26]. The ideal dimension of the parameters is determined using Eq. (4)

$$
Y=Y_{m}+\sum_{i=0}^{q} Y_{i}-Y_{m}
$$

Where $Y_{m}$ is the total mean Signal- to - Noise ratio, $Y_{i}$ is the mean optimum level and ' $q$ ' is the number of significant parameters. The main purpose of conducting the confirmation test is to assist the optimum parameter conditions that were proposed by the investigation which compared with the predicted value. Table 9 reported the optimal parameter settings of predicted and experimental values for obtaining the best result (i.e. Ultumate tensile strength and \% Elongation)

Table 9: Confirmation Experiment

\begin{tabular}{|c|c|c|c|c|}
\hline & $\begin{array}{c}\text { Optimum parameter } \\
\text { for Ultimate Tensile } \\
\text { Strength }\end{array}$ & $\begin{array}{c}\text { Optimum parameter } \\
\text { for \% Elongation }\end{array}$ \\
\hline & Prediction & Experiment & Prediction & Experiment \\
\hline Level & $\mathrm{A}_{1} \mathrm{~B}_{1} \mathrm{C}_{3}$ & $\mathrm{~A}_{1} \mathrm{~B}_{1} \mathrm{C}_{3}$ & $\mathrm{~A}_{1} \mathrm{~B}_{3} \mathrm{C}_{1}$ & $\mathrm{~A}_{1} \mathrm{~B}_{3} \mathrm{C}_{1}$ \\
\hline Response & 355 & 358 & 44 & 45 \\
\hline SNR & 51.03 & 52.01 & 32.71 & 32.98 \\
\hline
\end{tabular}

\section{Conclusions}

Present paper deals with the optimization (maximization) of responses (i.e., ultimate tensile strength and \% elongation) of brass under various temperature conditions of uniaxial tensile test. Taguchi design method provides the efficient optimum conditions for uniaxial tensile test. The following are the important concluding remarks obtained from the work.

1. The optimum conditions obtained for ultimate tensile strength for uniaxial tensile test was orientation level $1\left(0^{0}\right)$, temperature level 1 $\left(300^{0}\right)$ and strain rate level $3\left(0.001 \mathrm{~s}^{-1}\right)$.

2. The optimum conditions obtained for and $\%$ elongation for uniaxial tensile test was orientation level $1\left(0^{0}\right)$, temperature level 3 $\left(500^{0}\right)$ and strain rate level $3\left(0.1 \mathrm{~S}^{-1}\right)$.

3. The mathematical model generated for ultimate tensile strength was R-sq $=98.54 \%$, R-sq(adj) $=94.15 \%$ and $\%$ elongation was R$\mathrm{sq}=98.93 \%$, R-sq(adj) $=95.73 \%$ under tensile test having better regression fit as it closer $100 \%$.

4. From the confirmation experiment, test results have been verified and found that predicted and experimental results are very close and hence optimal parameter settings are recommended for sheet metal manufacturing applications in industries.

\section{References}

1. Hagenah, H., Schulte, R., Vogel, M., Hermann, J., Scharrer, H., Lechner, M. Merklein, M. CIRP ,79, 649 (2019).

2. Gronostajski, Z., Pater, Z., Madej, L., Gontarz, A., Lisiecki, L., Lukaszek-Solek, A., Luksza, J., Mróz, S., Muskalski, Z., Muzykiewicz, W., Arch. Civ. Mech. Eng., 19, 898 (2019)

3. Han, S.S. J. Mater. Process. Technol., 63, 129 (1997)

4. Wang, P.Y., Wang, Z.J., Xiang, N., Li, Z.X. J. Manuf. Process., 53, 364 (2020)

5. Reed-Hill, R.E., Abbaschian, R. PMP, (3rd ed., PWS-KENT: Boston, MA, USA, 691 1999)

6. Zaretsky, E.B., Kanel, G.I. J. Appl. Phys., 124, 045902 (2018).

7. Davoodi, A., Honarbakhsh, S., Farzi, G.A. Prog. Org. Coat, 88, 106 (2015).

8. Adineh, M., Doostmohammadi, H., Raiszadeh, R. Iran. J. Mater. Sci. Eng., 16, 21 (2019).

9. Sohn, S., Kang, T. J. Alloy. Comp., 335, 281 (2002).

10. Bydalek, A.W., Kula, A., Blaz, L., Najman, K. Arch. Foundry Eng., 19, 21 (2019).

11. Suárez, L., Rodriguez-Calvillo, P., Cabrera, J.M., Martinez-Romay, A., MajuelosMallorquin, D., Coma, A. Mater. Sci. Eng. A, 627, 42 (2015).

12. Humphreys, F.J., Hatherly, M. Chapter 13 (Elsevier: Pittsburgh, PA, USA, 2004). 
13. McQueen, H.J., Imbert, C.A.C. J. Alloy. Comp., 378, 35 (2004).

14. Spigarelli, S., Mehtedi, M.E., Cabibbo, M., Gabrielli, F., Ciccarelli, D. Mater. Sci. Eng. A, 615, 331 (2014).

15. Ashby, M.F., Gandhi, C., Taplin, (Elsevier: Cambridge, UK, pp. 1-31, 1983).

16. Wolley, D.J., Fox, A.G. J. Mater. Sci. Lett. 7, 763 (1988).

17. Ross PJ, (international edn. McGraw Hill, Singapore 1996).

18. Montgomery DC, 4th edn. (Wiley, New York 1997).

19. R.A. Fisher, Statistical Methods for Research Workers (Oliver and Boyd, London, 1925).

20. D. C. Montgomery, Design and analysis of experiments, (Wiley, Singapore, 1991).

21. Tanya Buddi, Swadesh Kumar Singh and B. Nageswara Rao, Materials Today: Proceedings 5, 18739 (2018).

22. Dharavath Balojia, Kalluri Anilb, K Sa,tyanarayanab, Ahsan ul haqc, Swadesh Kumar Singh, M.T.Naika, Materials Today: Proceedings, 18, 4475 (2019).

23. R. Philip, Taguchi techniques for quality engineering, (Tata McGraw Hill, New York 1996).

24. J. Santhakumar, U .Mohammed Iqbal, M.Prakash, IJMET, 8, 53 (2017).

25. Doddamani, S., Kaleemulla, M., Begum, Y. International Journal of Composite Material and Matrices, 1 , 1 (2015).

26. Johan Singh P, Guha B. Eng Fail Anal, 10, 1 (2003). 